\title{
A DINÂMICA DO SISTEMA DE PRODUÇÃO EM RELAÇÃO À EXTRAÇÃO DO PATAUÁ E A SUA CONTRIBUIÇÃO AMBIENTAL PARA O DESENVOLVIMENTO DA REGIÃO AMAZÔNICA NO MUNICÍPIO DE ANAJÁS-PARÁ
}

\section{ARTIGO ORIGINAL}

SILVA, Esther Cristiane Correa de Araújo da ${ }^{1}$

FEITOSA, Ana Delice Santos ${ }^{2}$

SILVA, Esther Cristiane Correa de Araújo da. FEITOSA, Ana Delice Santos. A dinâmica do sistema de produção em relação à extração do Patauá e a sua contribuição ambiental para o desenvolvimento da Região Amazônica no Município de Anajás-Pará. Revista Científica Multidisciplinar Núcleo do Conhecimento. Ano 05, Ed. 07, Vol. 01, pp. 56-70. Julho de 2020. ISSN: 2448-0959, Link de acesso: https://www.nucleodoconhecimento.com.br/meio-ambiente/extracaodo-pataua

\section{RESUMO}

A pesquisa tem como foco a dinâmica do sistema de produção em relação a extração do patauá e a sua contribuição ambiental para o desenvolvimento da região

\footnotetext{
${ }^{1}$ Mestre em Meio Ambiente e Desenvolvimento, Pós-graduação em Gestão Ambiental e Desenvolvimento Sustentável e no Ensino de Ciências, Graduação em Pedagogia e Biologia.

2 Doutorado em Ciências da Educação. Mestrado em Máster en Ciencias de la Educación. Especialização em Especialização Educação Especial. Especialização em Especialização em Políticas Públicas e Intervenção Social. Especialização em Especialização em Gestão, Orientação e Supervisão Escolar. Especialização em Especialização em Docência em Linguistica Espanhola. Graduação em Licenciado em Pedagogia em Regime Especial - Licenciatura Plena.
} 
amazônica no município de Anajás-Pará, com sua problemática sobre: qual a dinâmica de produção em relação a extração do patauá? A investigação foi de forma qualitativa descritiva com estudo bibliográfico e de campo, com o objetivo geral em analisar os fatores de desenvolvimento da extração do patauá em Anajás no Pará em Brasil, e os específicos de descrever as características do patauá; entender os benefícios e a extração do patauá e identificar a contribuição ambiental para a região de Anajás devido à extração do patauá. A hipótese da pesquisa foi que a dinâmica de produção da extração do patauá serve de contribuição para o sustento das famílias. A metodologia foi contemplada com entrevista para quinze sócios e ao chefe do escritório da Empresa de Assistência Técnica e Extensão Rural do Estado do Pará - EMATER, que estão envolvidos de forma direta e indiretamente com o desenvolvimento da associação do Guajará. Os resultados foram à confirmação e além da hipótese, que a produção do patauá contribui de forma significativa com a renda das famílias, e a formalização da associação foi em prol da melhoria da comunidade e consequentemente para a cidade.

Palavras chaves: Desenvolvimento, sustentabilidade, cultura, produção.

\section{INTRODUÇÃO}

A investigação visa o estudo da dinâmica do sistema de produção em relação a extração do patauá e a sua contribuição ambiental para o desenvolvimento da região

amazônica no município de Anajás-Pará, que fazem parte das questões socioambientais ambientais.

Devido a isso, a problemática em estudo visa: qual a dinâmica de produção em relação à extração do patauá? A investigação será de forma qualitativa e descritiva com estudo bibliográfico e de campo, com o objetivo geral em analisar os fatores de desenvolvimento da extração do patauá em Anajás no Pará em Brasil, e os específicos de descrever as características do patauá; entender a maneira de extração do patauá e identificar a contribuição ambiental para a região de Anajás devido à extração do patauá. 
A metodologia será realizada uma entrevista para quinze associados e ao chefe do Escritório Local da Emater em Anajás-Pa, que estão envolvidos de forma direta e indiretamente com o desenvolvimento da Associação de Produtores Rurais Natureza é vida (APRUNAV) na comunidade Belo Horizonte.

A estrutura do trabalho científico é composta por introdução, estrutura e problema da pesquisa descrito em síntese; o desenvolvimento se dividirá em quatro tópicos principais que são: os fatores de desenvolvimento da extração do patauá em Anajás no Pará em Brasil, nesse apresenta estudos bibliográficos relacionados aos objetivos apresentando os fatores; o segundo é sobre: as características do patauá, descrever as característica do produto e suas qualidades; terceiro sobre: a maneira de extração do patauá, entender como é feito a extração de maneira segura; o quarto tópico: a contribuição ambiental para a região de Anajás devido à extração do patauá, nesse tópico irá apresentar a identificação das contribuições ambientais que estão favorecendo na região de Anajás.

Em seguida resultados com as discussões de dados e considerações finais. A hipótese da pesquisa é que a dinâmica de produção da extração do patauá serve de contribuição para melhoria da renda familiar.

\section{OS FATORES DE DESENVOLVIMENTO DA EXTRAÇÃO DO PATAUÁ}

Os fatores de desenvolvimento da extração do patauá são os avanços das famílias referentes seus aspectos econômicos, político e social, pois as mesmas vendem suas produções para contribuir com a renda familiar.

O Instituto de pesquisa Amazônico- IPAM propõem o fomento na agricultura familiar, atuando lado a lado e com parcerias de entidades e empresas prestadoras de serviços que Ihes garantam uma receita adequada, através da valorização do produto, e com isso $o$ aumento na renda familiar.

Segundo Araújo (2005, apud Almeida 2010) os fatores que também está sendo amplamente discutido, é o meio ambiente, que é o desenvolvimento sustentável 
como peça chave para o futuro da humanidade. Por isso há necessidades quanto á tomada de decisões efetivas no campo das políticas voltadas para melhoria ambiental, não apenas no aspecto econômico, mais também no social.

Meirelles (2006) evidencia que as famílias em busca de garantir o seu sustento, acabam recorrendo a floresta em uma ação imediatista, por exemplo, a extração do palmito de açaí, que vem ocorrendo há décadas, e por não se tratar de uma fonte de renda estável, acaba por contribuir para o empobrecimento do ribeirinho e consequentemente o desmatamento da região.

De acordo com Meirelles (2006, p.233) "A miséria é a principal causa de destruição da floresta, em todos os sentidos". Situação que revela o descaso do poder público, favorecendo o aumento da violência, prostituição e do uso de entorpecentes. Algumas questões econômicas, políticas e sociais, contribuem para o desmatamento dentro da região Amazônica.

\section{BENEFICIAMENTO E A EXTRAÇÃO DO PATAUÁ}

A maneira de extração do patauá deve ter alguns cuidados, pois desde a colheita existe perigo, alguns animais peçonhentos se escondem na copa da árvore, sendo assim, o extrativista corre o risco de ser picado por algum desses animais. A maturação se dá também no período chuvoso, onde as palmeiras se encontram lisa, o que pode ocasionar acidentes. Nas demais fases do processo os riscos são quase zero.

A espécie demonstra possibilidades para o cultivo dentro da agricultura familiar, pois poderá levar a comunidade o melhoramento em seus aspectos econômicos, pois aproveita toda a planta desde a retirada do mesocarpo, que tem cerca de setenta e quatro porcentos de proteína, sendo que o mesmo são utilizados em vários produtos além do óleo. $O$ valor nutricional é equivalente com a carne e leite, sem falar a visão de mercado e exportação. $O$ que necessita são de parceiros que possam contribuir com o extrator para que alcance seus objetivos no melhoramento de suas vivências. 
Figura 1.

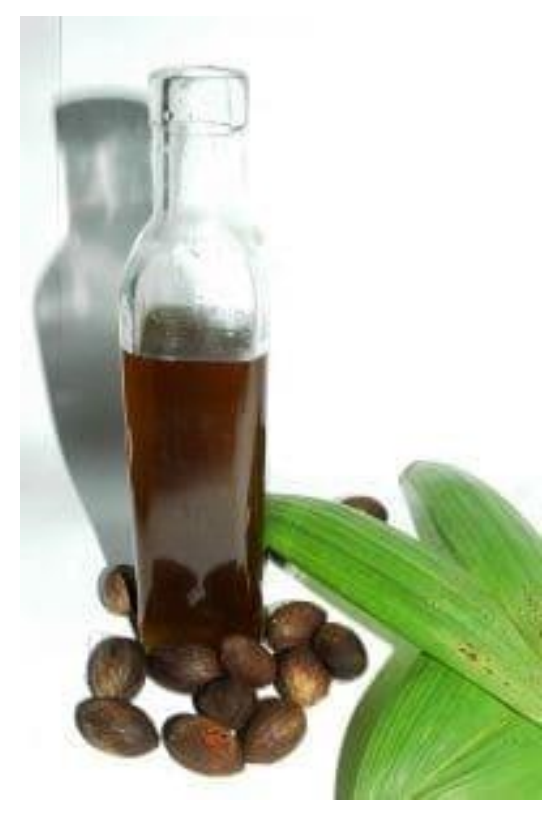

Fonte: site Amazonoil (2020).

Conforme Silva (2004, p. 203) "O nome que os cientistas dão para o patauá significa "fruto de vinho". Oeno quer dizer vinho e carpus quer dizer fruto (...) "O patauazeiro leva de 8 a 15 anos para frutificar e produz até 3 cachos por ano, com mais ou menos 16 quilos por cacho."

Após a colheita dos frutos de Patauá, os mesmos são colocados de molho em água com temperatura ambiente, onde permanecem por um período de 48 a 72 horas. Após esse período, os frutos são macerados para separação do mesocarpo da semente, onde o mesocarpo é levado a maquina de processamento para obtenção do suco ou vinho, que é mesma usada no processamento do açaí. Após a obtenção do suco ou vinho, o mesmo é colocado em um recipiente para ser levado ao fogo.

Quando esse suco ou vinho começa a ferver o óleo é liberado lentamente e o mesmo é retirado com auxílio de uma concha e colocado em outro recipiente menor. Depois que esse processo chega ao fim, o óleo coletado é fervido para retirada do excesso de água, coado para retirar as impurezas e vazados em garrafas pets. 


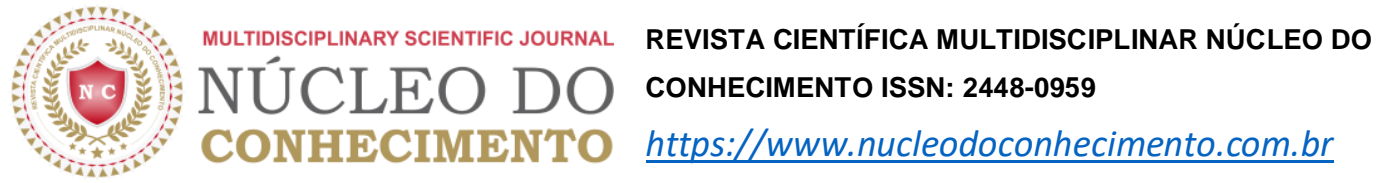

\section{AS CARACTERÍSTICAS DO PATAUÁ}

Figura 2.

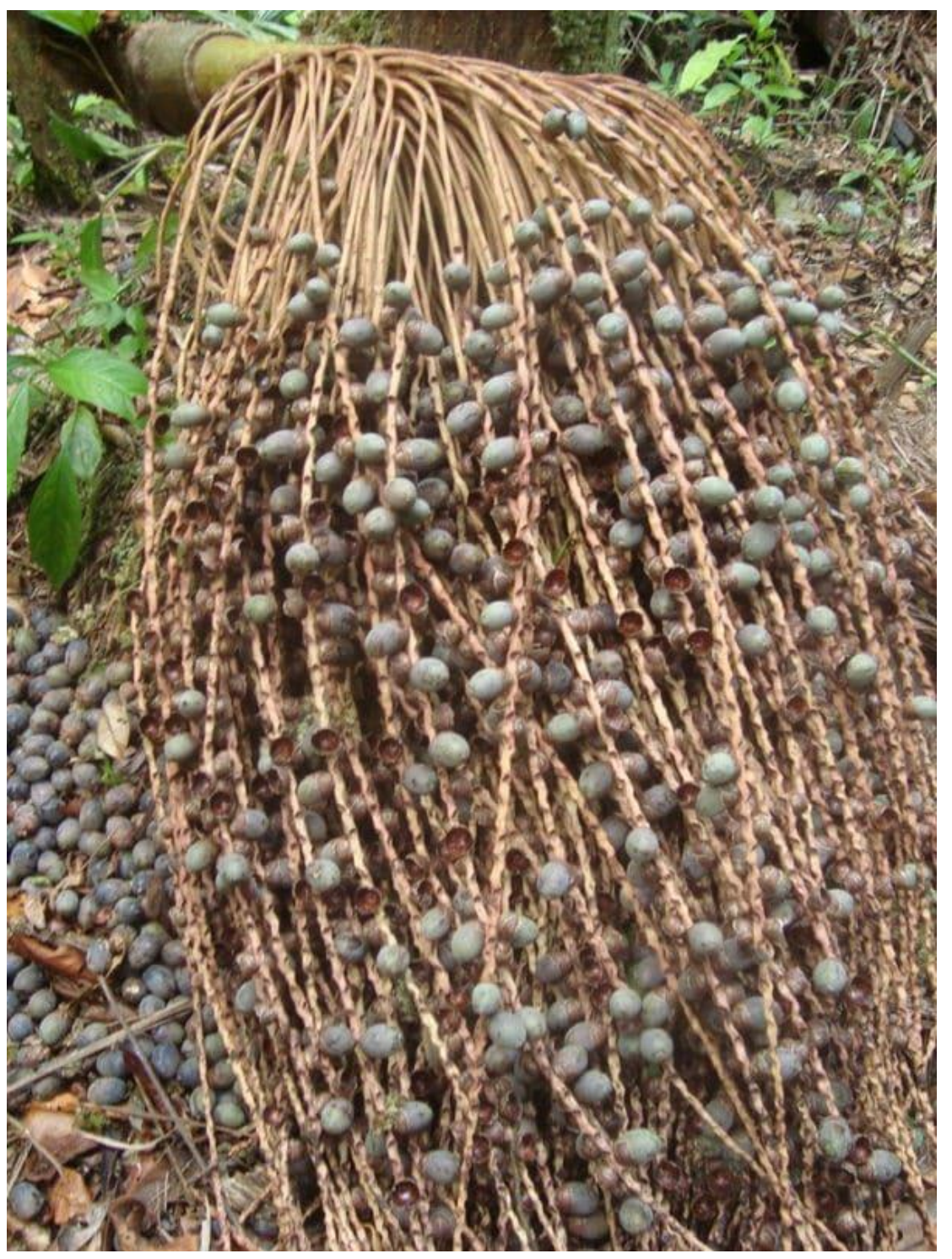

Fonte: site Amazonoil (2020).

De acordo Gomes (2004) patauá pertence à família botânica Arecaceae e gênero Qenocarpus. Qenocarpus é de origem grega e significa: oeno = vinho e carpus = fruto, "fruto de vinho", demonstrando a importância do suco elaborado a partir da polpa dos frutos. 
De acordo com Cavalcante (1991) faz uma descrição da espécie em estudo como uma palmeira inerme, de estipe ereto e único, porte alto, atingido de $4 \mathrm{~m}$ a $26 \mathrm{~m}$ de altura, com $25 \mathrm{~cm}$ a $54 \mathrm{~cm}$ de diâmetro, as suas folhas são compostas, pinadas, com a 16 folhas de planta, dispostas em espiral, medindo de $3 \mathrm{~m}$ a $10 \mathrm{~m}$ de comprimento, dotada de bainha grande, de coloração verde-escura com as margens fibrosas, por volta de $1 \mathrm{~m}$ de comprimento, e prolongadas em longos espinhos pretos e pecíolos persistentes por longo tempo na posição vertical.

Segundo Leitão (2008) enfatiza que o Brasil é um país detentor de umas das maiores diversidade biológico do planeta. Dentre as espécies da biodiversidade amazônica, são inúmeras as variedades de espécies frutíferas, muitas conhecidas apenas regionalmente e que embora possuam grande valor nutritivo e comercial, encontramse subaproveitadas economicamente.

Dentre estas variedades o patauazeiro é uma palmeira que cresce naturalmente na floresta, seu fruto é um auxilio na alimentação e serve como fonte de renda para o ribeirinho. É importante salientar que o patauá assim como outras culturas pode ser uma nova alternativa de renda e desenvolvimento para as comunidades ribeirinhas de Anajás.

\section{A CONTRIBUIÇÃO AMBIENTAL PARA A REGIÃO DE ANAJÁS DEVIDO A EXTRAÇÃO DO PATAUÁ}

O patauá assim como outras novas culturas podem ser uma nova alternativa de renda e desenvolvimento para as comunidades ribeirinhas de Anajás, pois com o crescimento populacional também se crescem os problemas socioeconômicos e ambientais. Para o desenvolvimento sustentável em determinada comunidade é importante conhecer os recursos disponíveis e os mecanismos que podem potencializar no desenvolvimento.

A contribuição ambiental para da comunidade na região de Anajás devido à extração do patauá é que visa à renda para sustento das famílias, principalmente a cidade de 
Anajás que fica localizada na mesorregião do Marajó, micro região dos furos de Breves.

Segundo o IBGE (2010), Anajás possui uma população de 24 mil habitantes, sendo que a maior parte vive na zona rural. Com uma área territorial de $6.991 \mathrm{~km}^{2}$. Ela teve sua origem em decorrência ao desenvolvimento da catequese no período colonial, quando os Jesuítas sediados em Chaves, ampliaram suas missões para interior da ilha do Marajó.

A economia do município se resume basicamente nas atividades do extrativismo de madeira, palmito e fruto de açaí, sendo o último a base da alimentação ribeirinha. No Município de Anajás também podemos destacar o extração de produtos não madeiros como sementes oleaginosas com destaque para as sementes de Murumuru, Andiroba e Patauá; além da pesca artesanal como fontes de renda e sobrevivência.(EMATER, 2018).

\section{RESULTADOS E DISCUSSÕES}

Figura 3. Localização geográfica do arquipélago do Marajó

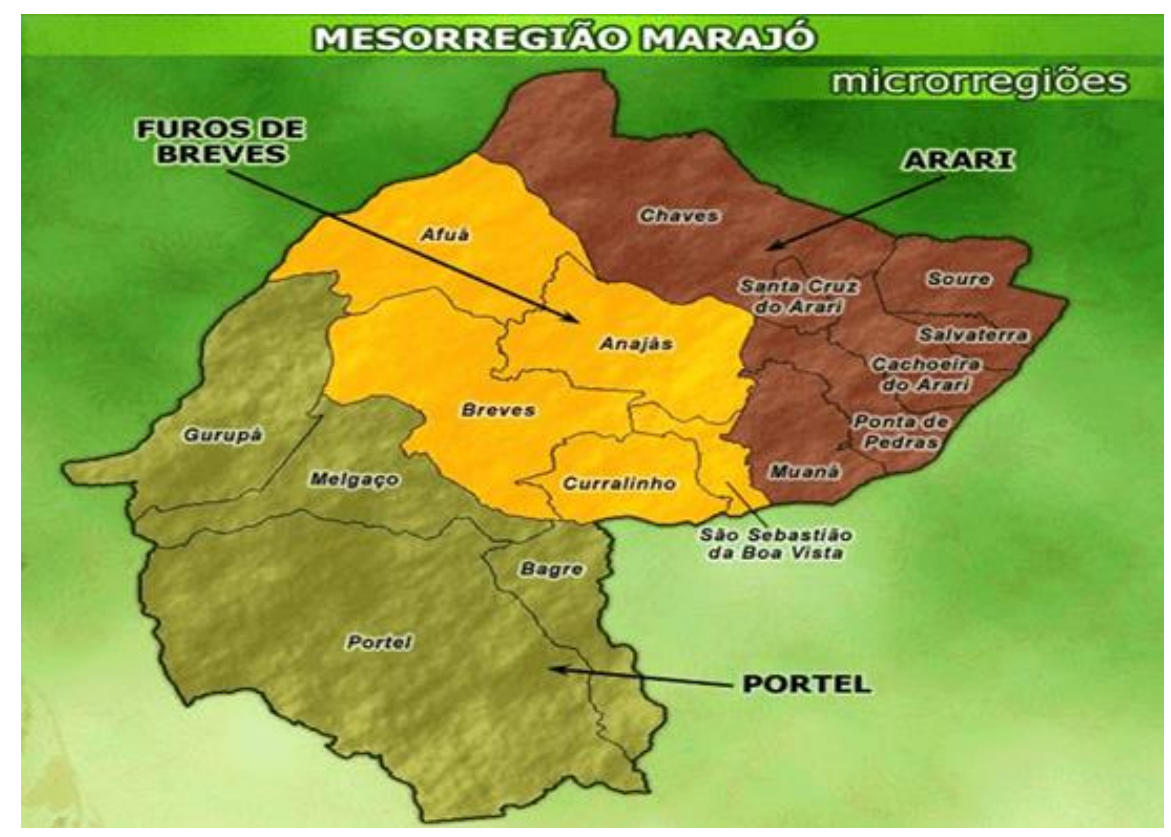

Fonte: PROATER (2017). 
A pesquisa se deu em Lócus na comunidade Mocambo do Guajará junto a Associação de Produtores Rurais Natureza é Vida (APRUNAV), que apresenta em torno de 150 famílias cadastrada que contam com o apoio da Empresa de Assistência Técnica e Extensão Rural-EMATER, através do Escritório Local em Anajás.

A Vila central da comunidade, denominada Mocambo do Guajará fica localizada na zona rural do Município de Anajás com aproximadamente $81,4 \mathrm{~km}$ de distância em linha reta, onde o meio de transporte são embarcações que levam em média 7 horas, ou voadeira e até rabetas, onde o tempo de viagem é inferior.

E importante salientar que a associação não faz parte dos programas de aquisição de alimentos, apesar da existência do Programa de Aquisição de Alimento- PNAE, pois a prefeitura através da secretaria municipal de educação não demonstra interesse, porém essa realidade não é exclusiva dessa região, mas infelizmente em todo o município de Anajás.

O técnico responsável chefe do escritório da EMATER em Anajás-Pa, o senhor José Nilton P. da Silva participou da pesquisa respondendo cinco questões da entrevista, sendo que a primeira pergunta foi: qual a dinâmica de produção em relação à extração do patauá? Segundo ele é a relação entre o produtor, associação, empresa que processa o óleo e consumidor. É através dessa articulação que há o sentido da dinâmica, desde a colheita até consumidor.

$\mathrm{Na}$ segunda questão sobre: quais as características de qualidade apresentam o patauá? Segundo ele, é realizada a análise do produto e foi constatada que é de excelente qualidade, até porque está no mercado.

Mambrim y Arellano (1997; p. 158)."Los aceites y grasas obtenidos de frutos de las palmeras de la región amazónica poseen características técnicas para su utilización en alimentos mas son necesarios estudios complementários (...), de la tecnología disponible para la explotación".

O texto acima enfatiza que o estudo e análise, e isso vem sendo feito segundo o participante da pesquisa. Na terceira questão: como acontece a comercialização do 
produto? A resposta foi: que após o óleo ser extraído e vazado em recipientes como garrafas pet's, os produtores levam até a sede da associação, chegando lá esse óleo após pesado é colocado em recipientes do tipo bombonas, e dependendo da produtividade se estabelece um fluxo que pode ser semanal ou quinzenal, são encaminhados para Belém. Percebe-se que a associação e produtor trabalham sozinhos sem uma parceria com a prefeitura.

Na quarta questão sobre: qual a contribuição ambiental para a região de Anajás devido à extração do patauá? Segundo o participante: se compararmos as mais variadas formas de extrativismo que acontece no âmbito da floresta pode se afirmar que a atividade de extração de óleo de patuá muito contribui, pois, a mesma não há desmatamento da floresta.

Na quinta pergunta: de que maneira a extração do patauá é realizada no município de Anajás? Segundo ele após a colheita e debulha dos frutos, os mesmos são colocados de molho em água com temperatura ambiente por um período de 48 a 72 horas. Após esse período, os frutos são macerados para separar a poupa do caroço. Essa poupa é processada para produção do suco de patauá. Logo em seguido esse suco é levado ao fogo, que no processo de fervura libera o óleo.

Percebe-se que há uma mão-de-obra elevada desde a colheita ao processamento, e necessita de equipamento que pode ajudar os agricultores nesse processo, e isso pode acontecer com a contribuição e parceria com entidades governamentais entre elas a prefeitura municipal.

O Instituto de pesquisa Amazônico- IPAM propõem o fomento na agricultura familiar, atuando lado a lado e com parcerias de entidades e empresas prestadoras de serviços que Ihes garantam uma receita adequada. A prefeitura poderia somar junto a essa parceria para além do desenvolvimento dos produtores, a cidade também estará no patamar de desenvolvimento. 
Figura 4. Vista aérea de uma parte da Comunidade do Guajará.

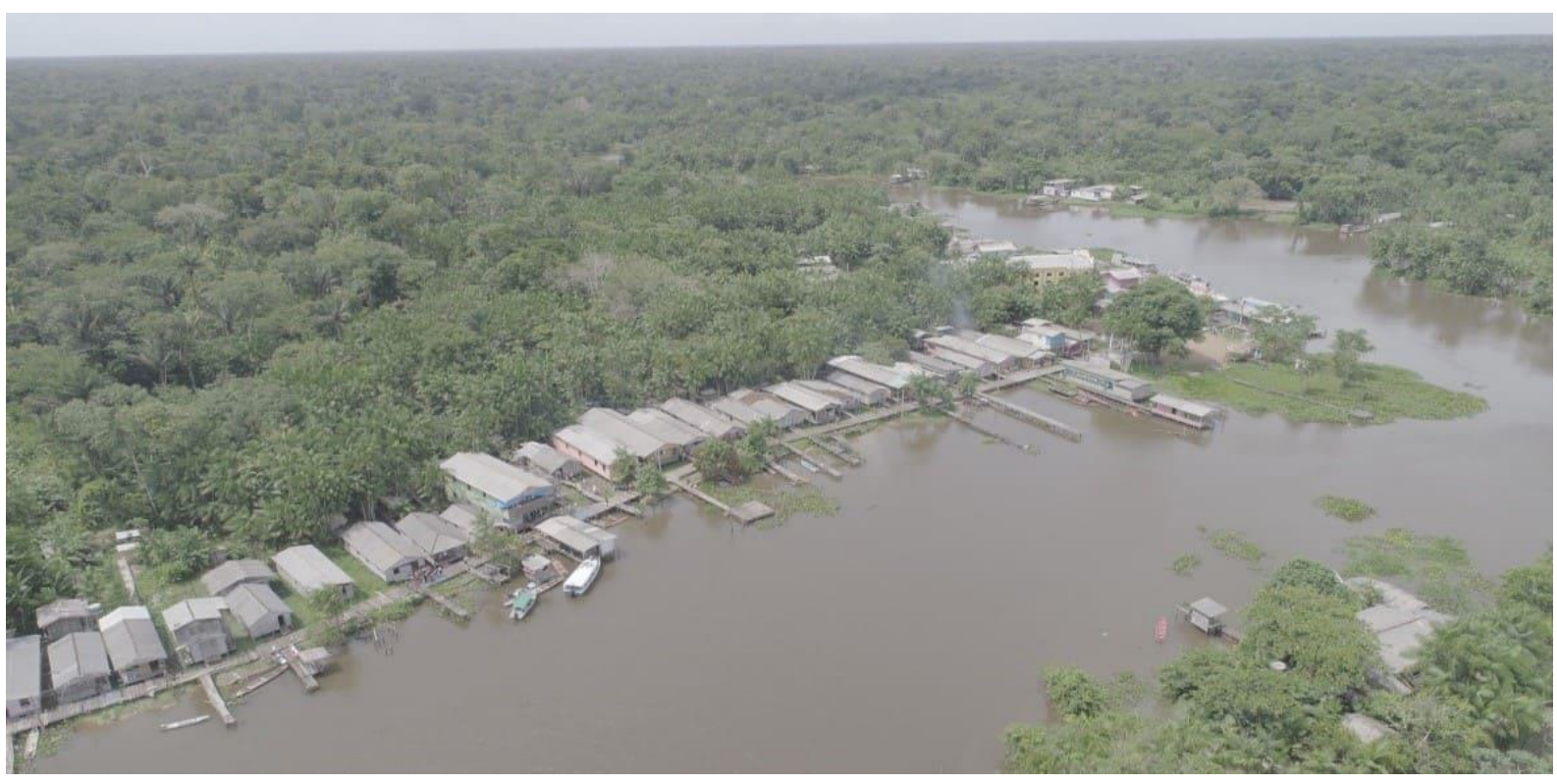

Fonte: EMATER (2017).

A próxima etapa da entrevista foi realizada com quinzes associados, sendo que a primeira questão sobre: como a associação se organiza de forma dinâmica em benefício aos associados diante da produção do patauá? Segundo eles através das assembleias, os associados decidem aonde vão ser utilizados os recursos da repartição de benefícios que são liberados a cada ano.

Na segunda questão sobre: qual o procedimento que a associação adota referente à lucratividade com a aquisição do patauá? Segundo eles: como a associação é uma entidade sem fins econômicos não há lucratividade, porém a empresa que adquire o produto adota a política de repartição de benefícios, onde a cada um ano de comercialização de subprodutos oriundos do óleo de patauá, um percentual é retornado à comunidade como repartição de benefícios.

As coletas de fruto de Patauá pelas famílias envolvidas na comunidade nos anos de 2015 a 2017 se somaram aproximadamente 100 toneladas, segundo o técnico da EMATER-PARÁ, que depois de processado artesanalmente se obteve aproximadamente 07 toneladas de óleo de patauá. Porém, o potencial na região é muito maior, segundo informações repassadas pelos comunitários. 
No momento da entrevista foi perguntado o grau de escolaridade dos participantes, e que $99 \%$ são analfabetos e $1 \%$ tem o ensino fundamental incompleto.

Gráfico 1. Grau de escolaridade dos entrevistados.

\section{Dados obtidos no momento da entrevista: grau de escolaridade}

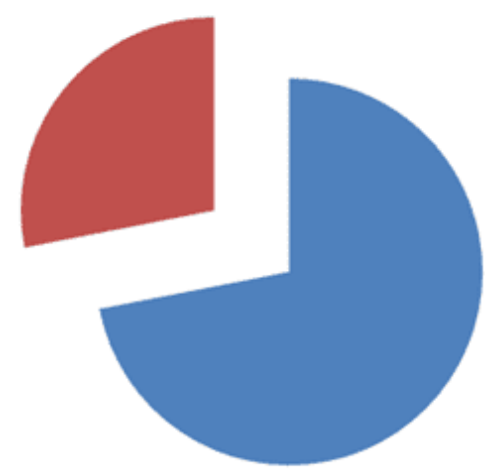

- $99 \%$ analfabetos

w $1 \%$ ensino fundamental incompleto

Fonte: o próprio autor (2020)

Percebe-se que o analfabetismo é um obstáculo para a busca de parceria, porque a falta de conhecimento aprisiona cada sócio em um mundo limitado de informação, por esse motivo a relevância de atividades educativas e projetos que visam o incentivo desses sócios estarem presente nas escolas, adentrando neste mundo do conhecimento e navegando no universo de seus direitos.

$\mathrm{Na}$ terceira questão sobre: quais os procedimentos que a comunidade e associação realizam para preservar o cultivo e colheita do patauá? Segundo eles, em Anajás a exemplo do açaizal, as áreas com ocorrência de patauá também são nativas, e no caso do patauá por ser uma cultura perene e para a extração de óleo não se derruba a árvore. Sendo assim, os produtores não cultivam tal espécie.

$\mathrm{Na}$ quarta questão que tipo de segurança e cuidados com o meio ambiente a associação favorece a mata devido à extração do patauá? Segundo eles, é elevada a preocupação da preservação com o meio ambiente na luta contra o desmatamento, 
pois como essa atividade se dá geralmente no período de entre safra do açaí, muitos produtores deixaram de extrair o palmito de açaí, que era sua única fonte de renda nesse período, e passaram a comercializar o óleo, fazendo com que a mata ficasse em pé, principalmente os açaizais, que são suas principais fontes de renda.

\section{CONSIDERAÇÕES FINAIS}

A presente investigação teve seu foco na dinâmica do sistema de produção em relação a extração do patauá e a sua contribuição ambiental para o desenvolvimento da região amazônica no município de Anajás-Pará, a pesquisa foi de forma qualitativa descritiva com estudo bibliográfico e de campo realizado uma entrevista com o chefe da EMATER e quinze sócios.

O objetivo geral foi analisar os fatores de desenvolvimento da extração do patauá em Anajás no Pará em Brasil, e seus fatores foram analisados, que contribui com os aspectos econômicos e sociais das famílias que fazem parte da produção. Os específicos foram de descrever as características do patauá, que tem seu brilho estampado nos lindos frutos e que predomina o óleo de excelente qualidade; entender os benefícios e extração do patauá, a maneira da colheita é cautelosa, principalmente em tempos chuvosos, porque se alojam animais peçonhentos que podem picar os produtores extratores causando lesões ou até mesmo a morte e seu beneficiamento está ligado ao sustento da família.

O último objetivo é de identificar a contribuição ambiental para a região de Anajás devido à extração do patauá, isso foi retratado nos fatores de desenvolvimentos, porém para ressaltar a contribuição está na renda familiar dos produtores que fazem parte da produção e que consequentemente a cidade também.

A problemática em estudo foi sobre: qual a dinâmica de produção em relação à extração do patauá? E os resultados foram que a hipótese foi confirmada: a produção do patauá contribui com a renda familiar, e mais além que a formalização da associação foi em prol da melhoria da comunidade, sendo que ainda buscam a parceria da prefeitura. 
Espera-se que através deste estudo que sejam implantados melhorias de condições através de incrementos das políticas de valorização dos produtos advindos da floresta, exemplo, o extrativismo, entre eles a agricultura familiar, pois através do fomento na cultura do patauá abrem-se as portas para uma nova alternativa de renda, e consequentemente a melhoria de vida dentro das comunidades ribeirinhas, associação e cidade como todo.

Logo a chave seria conhecer o que existe de recursos humanos e naturais disponíveis dentro da comunidade como o todo e os mecanismos que podem potencializar a matéria prima disponível na floresta, a prefeitura inserir a associação em projetos de aquisição de alimentos para que obtenha um desenvolvimento sustentável, e também projetos que visam à preservação do meio ambiente com atividades educativas.

Que a associação possa ir à busca de seus direitos participando de políticas públicas e entrando em contato com o governo federal para que juntos possam evoluir em suas produções com apoio de tecnologia que contribua com o manuseio e extrato do patauá.

\section{REFERÊNCIAS}

ALMEIDA, Josimar Ribeiro. Gestão Ambiental para o Desenvolvimento Sustentável. \{3. reimpr.\} Rio de janeiro: thex: Almeida Cabral, 34-55. 2010.

AMAZONOIL. Site disponível: https://www.amazonoil.com.br/. Acesso em 20 de maio de 2020.

AMAZONOIL. Site disponível: https://dev.amazonoil.com.br/pt/pataua/. Acesso em 20 de maio de 2020.

CAVALCANTE, Paulo B. Frutas comestíveis da Amazônia - 5ª Edição. Museu Paraense Emilio Goeldi. Edições Cejup. Belém - PA 1991.

EMATER, Empresa de Assistência Técnica e Extensão Rural do Estado do Pará.

Disponível em: http://www.emater.pa.gov.br/. Acesso em 14 de maio de 2020. 
GOMES-Silva, Daisy Aparecida Pereira. Ecologia e Manejo de Patauá (Oenocarpus bataua Mart.) para Produção de Frutos e Óleo. 2004. Disponível em: https://ainfo.cnptia.embrapa.br/dig. Acesso em 20 de maio de 2020.

IBGE, Instituto Brasileiro de Geografia e Estatística. Cidades. 2010. Disponível em: www.cidades.igge.gov.br. Acesso em 10 de Dezembro de 2016.

IPAM, Instituto de Pesquisa Ambiental da Amazônia. Realização de estudo de cadeias produtivas ligada ao sistemas integrados de produção, ao extrativismo e aos produtores da sociobiodiversidade $\mathrm{Na}$ região de influência da rodovia BR-163 (Cuiabá-Santarém), no estado do Pará. (2012). 20-50pp.

\section{LEITÃO, A.M. Caracterização morfológica e físico-química de frutos e sementes} de Astrocaryum aculeatum Meyer. 2008. Disponível em: (Arfile:///C:/Users/Esther/Downloads/374-1559-1-PB.pdf). Acesso em 10 de Dezembro de 2016.

MAMBRIM,M. C.T.; Barrera-Arellano, D.(1997). Caracterización de aceites de frutos de palmeras de la región amazónica del Brasil, Laboratorio de Óleos e Gorduras - FEA / UNICAMP -Vol. 48. Fase. 3), 154-158 Campinas, SP Brasil.

MEIRELES. F., João Carlos, (2006). O Libro de Ouro da Amazônia.5ed.- Rio de Janeiro: Ediouro; 233-235.

ÓLEO PATAUÁ. Disponível: http://www.amazonoil.com.br/produtos/oleos/pataua.htm. Acesso em 20 de maio de 2020.

PATAUÁ. Disponível em: http://www.cifor.org/publications/pdf_files/Books/BShanley1001/203_208.pdf. Acesso em 20 de maio de 2020.

PROATER, Empresa de Assistência Técnica e Extensão Rural do Estado do ParáEMATER-PA. 2016. 
SILVA, Deisy A. P. G. Ecologia e Manejo de patauá (Oenocarpus bataua Mart.) para produção de frutos e óleo. Documentos, 88. Embrapa. Rio Branco, AC. 2004 http://oaji.net/articles/2016/2238-1456160300.pdf. Acesso em 19 de maio de 2020.

\section{ANEXO}

Questionário- Técnico responsável chefe do escritório da EMATER em Anajás$\mathrm{Pa}$

1. Qual a dinâmica de produção em relação à extração do patauá?

Produtor extrator - associação - empresa que processa o óleo - empresa que transforma em produto final para o consumo.

2. Quais as características de qualidade apresentam o patauá?

Segundo análise laboratorial feita pela empresa que compra o produto, o mesmo tem uma alta qualidade.

3. Como acontece a comercialização do produto?

Após o óleo ser extraído e vazado em recipientes como garrafas pet's, os produtores levam até a sede da associação, chegando lá esse óleo após pesado é colocado em recipientes do tipo bombonas, e dependendo da produtividade se estabelece um fluxo que pode ser semanal ou quinzenal, são encaminhados para Belém.

4. Qual a contribuição ambiental para a região de Anajás devido à extração do patauá?

Se compararmos as mais variadas formas de extrativismo que acontece no âmbito da floresta pode se afirmar que a atividade de extração de óleo de patuá muito contribui, pois a mesma não há desmatamento da floresta.

5. De que maneira a extração do patauá é realizada no município de Anajás? 
Após a colheita e debulha dos frutos, os mesmos são colocados de molho em água com temperatura ambiente por um período de 48 a 72 horas. Após esse período, os frutos são macerados para separar a poupa do caroço. Essa poupa é processada para produção do suco de patauá. Logo em seguido esse suco é levado ao fogo, que no processo de fervura libera o óleo.

\section{Questionário para os associados}

1. Como a associação se organiza de forma dinâmica em benefício aos associados diante da produção do patauá?

Através das assembleias, os associados decidem aonde vão ser utilizados os recursos da repartição de benefícios que são liberados a cada ano.

2. Qual o procedimento que a associação adota referente à lucratividade com a aquisição do patauá?

Como a associação é uma entidade sem fins econômicos não há lucratividade, porém a empresa que adquire o produto adota a política de repartição de benefícios, onde a cada um ano de comercialização de subprodutos oriundos do óleo de patauá, um percentual é retornado à comunidade como repartição de benefícios.

3. Quais os procedimentos que a comunidade e associação realizam para preservar o cultivo e colheita do patauá?

Em Anajás a exemplo do açaizal, as áreas com ocorrência de patauá também são nativas, e no caso do patauá por ser uma cultura perene e para a extração de óleo não se derruba a arvore. Sendo assim, os produtores não cultivam tal espécie.

Enviado: Junho, 2020.

Aprovado: Julho, 2020. 